\title{
Uma metodologia para diagnóstico de clima organizacional: integrando motivos sociais e cultura brasileira com fatores do ambiente de trabalho do Poder Judiciário*
}

\author{
Beatriz Quiroz Villardi** \\ Viviane Narducci Ferraz*** \\ Veranise Jacubowski Correia Dubeux****
}

\begin{abstract}
SumÁRıo: 1. Introdução; 2. Metodologia da pesquisa; 3. Gestão estratégica de pessoas e diagnóstico de clima organizacional; 4. Cultura organizacional e traços culturais brasileiros; 5. Estudo de caso no Poder Judiciário; 6. Considerações finais.
\end{abstract}

Summary: 1 . Introduction; 2. Research methodology; 3 . Strategic human resources management and organizational climate diagnosis; 4. Organizational culture and Brazilian cultural characteristics; 5. Case study about Judiciary management; 6 . Final considerations.

\footnotetext{
* Artigo recebido em mar. 2009 e aceito em out. 2010.

** Professora adjunta e vice-coordenadora do Programa de Pós-Graduação Gestão e Estratégia em Negócios (PPGEN) da Universidade Federal Rural do Rio de Janeiro (UFRRJ). Doutora e mestre em administração pelo IAG/PUC-Rio. Endereço: BR-465, km 7 - CEP 23890-000, Seropédica, RJ, Brasil. E-mails: rbvillardi@hotmail.com; bqv2008@ufrrj.br.

*** Professora convidada do FGV Management, na área gestão de recursos humanos. Tecnologista sênior da Fundação Instituto Brasileiro de Geografia e Estatística (IBGE). Doutoranda em administração e mestre em administração pública pela Fundação Getulio Vargas (Ebape/FGV-RJ). Endereço: Praia de Botafogo, 190, 4 andar - Botafogo - CEP 22250-900, Rio de Janeiro, RJ, Brasil. E-mails: narducci@fgvmail.br; vnarducci@uol.com.br.

**** Professora e coordenadora da área de métodos quantitativos do curso de administração da PUC-Rio. Pesquisadora do Centro de Altos Estudos de Propaganda e Marketing (CAEPM) e professora da ESPM-Rio. Doutora em engenharia mecânica pela Coppe, da Universidade Federal do Rio de Janeiro (UFRJ). Mestre em ciências da engenheira civil pela Coppe (UFRJ). Área de atuação: levantamento e análise estatística de banco de dados, modelos quantitativos para previsões de vendas e modelagem computacional. Endereço: IAG, PUC-Rio. Rua Marquês de São Vicente, 225 — Gávea - CEP 22451-900, Rio de Janeiro, RJ, Brasil. E-mails: veranise.dubeux@iag.puc-rio. br; veranise.dubeux@uol.com.br; vdubeux@espm.br.
} 
Palavras-chave: diagnóstico de clima organizacional; ferramentas quantitativas e qualitativas para coleta de dados; traços culturais brasileiros; gestão de pessoas com subjetividade no setor público; motivos sociais e fatores do clima organizacional.

Key words: Organizational climate diagnosis; qualitative and quantitative tools for data collection; Brazilian cultural characteristics; subjectivity in human resources public administration; social motives and organizational climate.

Neste artigo examinam-se a concepção e a elaboração de uma metodologia para realização de diagnóstico de clima organizacional (DCO) com uma ferramenta quantitativa que considera as especificidades do Poder Judiciário. Para tal identificaram-se em um Tribunal Regional de Justiça sete fatores de clima organizacional e três traços culturais. Nesta pesquisa exploratória os dados foram gerados por meio de pesquisa bibliográfica, documental, observação direta e entrevistas em profundidade que, interpretados qualitativamente, revelaram três traços culturais inter-relacionados: o autoritarismo, a centralização e o pessoalismo mediando três motivos sociais e sete fatores de clima organizacional. Os resultados do projeto-piloto indicaram que os motivos sociais de realização dos serventuários merecem maior atenção dos seus gestores que os de afiliação e de poder. Embora tivesse sido proposta uma ferramenta de análise quantitativa para minimizar a subjetividade no processo de DCO, percebeu-se que esta permeia a percepção dos gestores mediada por seus traços culturais, explicitando indissociabilidade entre objetividade-subjetividade da gestão de pessoas nessa organização. Por fim, apontam-se recomendações para a implantação da ferramenta DCO considerando suas especificidades.

\section{A methodology for organizational climate diagnosis: integrating social motives and} Brazilian culture characteristics to working factors in judiciary organization

This paper examines the conception and elaboration process of an organizational climate diagnosis (OCD) methodology that considers judiciary organization specificity. In this direction seven organizational climate factors and three cultural characteristics of this public organization were identified. Data was generated through bibliographic research, field observation and in depth interviews which were qualitatively interpreted. Three intertwined cultural characteristics were revealed: authoritarism, centralization and personalism pervading three social motives and seven organizational climate factors. Preliminary results obtained through a pilot project results indicate that public workers self fulfillment motives deserve more manager's attention than those concerning affiliation and power motives. Although a methodology and a quantitative tool for OCD were elaborated in order to minimize managers' subjectivity during OCD conception process, it was noticed that subjectivity pervades managers perception intertwined with their organizational cultural characteristics. In this way objectivity-subjectivity intertwining was revealed as well as respondents' subjectivity mediating human resources management. Finally, recommendations for OCD implementation considering judiciary organization specificity are presented. 


\section{Introdução}

Diante das rupturas e mudanças, cada vez mais intensas e frequentes no mundo contemporâneo, reconhece-se que para as organizações "o grande desafio é, sem dúvida, conseguir dominar a mudança" (Bergamini, 2002:112). Dominar a mudança por meio da gestão de pessoas significa priorizá-las como diferencial estratégico da organização. Para tanto, modelos tradicionais que privilegiam o planejamento e controle, tal como os propostos por Taylor e as funções de comando de Fayol, se mostram inadequados. Surge então o conceito de gestão estratégica de pessoas, pelo qual, a partir de ações interdependentes nos subsistemas próprios de Recursos Humanos (RH), pretende-se alinhar as políticas de pessoal às estratégias organizacionais ao invés de atuar de modo pontual, isoladamente (Hanashiro, 2007).

Reconhece-se também que os indivíduos nas organizações atuam de acordo com valores, pressupostos e crenças compartilhadas, que constituem sua cultura organizacional (Freitas, 1997), e que os indivíduos não podem ser dissociados em suas emoções e experiências por sua própria natureza humana (Davel e Vergara, 2001).

O reconhecimento da existência de traços culturais e da indissociabilidade das experiências e emoções dos indivíduos sugere que a implementação bem-sucedida de um modelo de gestão de pessoas estaria diretamente relacionada à consideração dos traços culturais dessa organização. Como então, considerando-se a gestão estratégica de pessoas, operam a subjetividade e os traços culturais dos próprios gestores da organização diante dos fatores do ambiente de trabalho? O modelo de gestão de pessoas do setor privado atende também ao setor público? Quais as especificidades das organizações públicas?

No setor privado, parece já reconhecida a relevância da proposta de gestão estratégica de pessoas e sua capacidade para obtenção de vantagens competitivas para as organizações. Já a gestão no setor público, entretanto, encontra-se ainda em processo de modernização com vistas a aumentar a eficiência e a qualidade na prestação dos serviços públicos, como propõe a denominada Administração Pública Gerencial (APG). Como, então, nesse contexto se realizaria uma gestão de pessoas para organizações públicas? Como elaborar uma proposta para o diagnóstico de clima organizacional (DCO) e um programa motivacional pertinentes?

O presente artigo integra um estudo iniciado em 2004, onde se discutiu a pertinência do modelo de APG para propiciar mudança de gestão e de cultura organizacional no Poder Judiciário brasileiro. O Projeto de Modernização e Reforma do Estado previa a implantação de uma ferramenta de gestão profissional: 
diagnóstico de clima organizacional (DCO) que, embora reconhecido na administração privada, demandou ajustes na concepção metodológica para que fosse pertinente à realidade do serviço público. Portanto, neste estudo se examinou e propôs uma metodologia para DCO, solicitada por um Tribunal Regional de Justiça, que atendesse suas especificidades tanto cultural como organizacional.

A Administração Pública Gerencial (APG), definida em 1995 a partir do Plano Diretor da Reforma do aparelho do Estado, reconhece a necessidade de romper com os modelos tradicionais de administração dos serviços públicos e fomenta que as organizações públicas adotem, com as devidas adequações, padrões de gestão desenvolvidos para ambientes das empresas privadas (Bresser-Pereira e Spink, 1998). Tais adequações seriam necessárias, visto que a administração pública preocupa-se com a efetividade, além de sua eficiência e eficácia. No caso do Poder Judiciário, seus objetivos e compromissos incluem a distribuição oportuna de justiça ao cidadão e à sociedade brasileira, além de otimização de custos e de cumprimento dos objetivos traçados internamente.

Fundamentadas em estudo empírico sobre a implantação de Avaliação e Desempenho por Competências num Tribunal Estadual de Justiça na administração pública, Narducci e colaboradores (2006) mostraram que a gestão de pessoas torna-se ainda mais complexa quando considera os traços e valores culturais brasileiros coexistentes aos traços e valores da burocracia estatal e os específicos àqueles de cada subcultura funcional e identidade profissional.

Assim, este artigo examina o processo de elaboração da metodologia para DCO e apresenta uma ferramenta quantitativa modificada após a realização de um projeto-piloto exploratório de DCO, que foi composto por ferramentas de análise qualitativa e quantitativa especificamente elaboradas.

O artigo está assim estruturado: contextualização inicial, metodologia da pesquisa, revisão de literatura sobre clima organizacional e motivos sociais dos indivíduos nas organizações, administração pública gerencial, cultura organizacional e traços culturais brasileiros. Prossegue com os resultados do projeto-piloto de DCO e uma discussão empírico-conceitual. Por fim, apresentam-se recomendações para a implantação da ferramenta e para futuras pesquisas.

\section{Metodologia da pesquisa}

Neste artigo focam-se a concepção de uma metodologia para DCO e as recomendações para sua posterior implantação por gestores de um Tribunal Regional de Justiça. Na primeira fase da pesquisa bibliográfica, selecionaram-se 
a teoria motivacional e a de clima e cultura organizacional para fundamentar a elaboração das ferramentas para DCO (um roteiro de entrevistas e um questionário). Os traços da cultura organizacional revelados neste tribunal foram identificados empiricamente ao longo de quatro meses por meio de entrevistas em profundidade, observação direta em visitas aos locais de trabalho e validados pela apresentação dos resultados preliminares aos serventuários gestores diretamente envolvidos.

Inicialmente, identificou-se o estudo aplicado de Gutierrez (1988) a uma empresa privada gaúcha, com base nos estudos de Souza (1980; 1982) realizados em uma empresa estatal. Ambos os autores, com base em Kolb e Litwin e em Stringer e McClelland, explicaram as dimensões componentes da motivação humana identificando empiricamente três motivos sociais das pessoas: afiliação, poder e realização.

Trata-se de um estudo de caso instrumental, nos termos de Stake (1994), cujas evidências empíricas resultantes do projeto-piloto para DCO serviram para gerar insights sobre as dificuldades e traços culturais presentes e ajustar a metodologia para DCO à realidade do Tribunal Regional de Justiça sob estudo. Na segunda fase, exploratória, realizou-se: pesquisa de campo na sede do Tribunal Regional de Justiça e pesquisa documental sobre o Programa de Modernização da Gestão no Poder Judiciário. Também se aplicou a técnica de observação direta por 30 dias nos gabinetes da Direção, além de entrevistas em profundidade, com a utilização de roteiro. Onze sujeitos foram entrevistados, em duas rodadas, para moldar a concepção da metodologia para DCO: um responsável pela comissão estratégica de gestão; dois assessores da Presidência do Tribunal; um diretor-geral da área jurisdicional e dois membros de sua equipe; um diretor-geral da área administrativa, dois serventuários da área jurisdicional e dois serventuários da área administrativa. Os sujeitos da pesquisa foram selecionados pelo critério de "bola de neve" (snowball) devido à sensibilidade que o tema "modernização da gestão pública" despertava nos serventuários e às intensas reações defensivas que o anúncio da realização de uma pesquisa para DCO provocava.

Este estudo limitou-se a configurar fatores do ambiente de trabalho e traços culturais revelados, associando-os a motivos sociais visando propor uma metodologia para DCO que, posteriormente, subsidiará programas de motivação específicos à realidade deste tribunal. O método de análise de conteúdo por categorias, proposto por Bardin (1977), orientou a interpretação qualitativa das entrevistas em profundidade com roteiro. O questionário para DCO aplicado no projeto-piloto foi analisado descritivamente sem propósito de generalização. 
Reconhecem-se limitações dos métodos e técnicas utilizados. As entrevistas coletaram apenas as declarações; a observação direta, os comportamentos observáveis dos serventuários. A capacidade dos pesquisadores em conduzir as entrevistas restringiu a qualidade das mesmas e também o uso do método de análise de conteúdo. Para superar essas limitações foi empregada a triangulação de fontes dos dados de campo e procurou-se alcançar objetivação, ou seja, "olhar o que é e não o que se deseja ver" (Demo, 1989). Neste artigo, a proposta de APG não foi questionada, embora se reconheçam válidas as críticas de Paula (2005) e Misocsky (2002) sobre sua falta de efetividade, assim como sua postura acrítica.

\section{Gestão estratégica de pessoas e diagnóstico de clima organizacional: definição e fatores motivacionais}

A relevância conferida ao elemento humano nas organizações não está restrita apenas a sua participação no processo produtivo. As pessoas "constituem o princípio essencial de sua dinâmica, conferem vitalidade às atividades e processos" (Davel e Vergara, 2001:31). Entretanto, embora se acredite no valor estratégico da área de RH das organizações, Hanashiro (2007) aponta que um estudo realizado pela Associação Brasileira de Recursos Humanos (ABRH) ressalta o descompasso entre a literatura, que apresenta o elemento humano como um ativo estratégico, e a realidade organizacional.

As práticas de gestão de pessoas no Brasil surgiram influenciadas pelo contexto político, econômico e social do país. Na tentativa de acompanhar as mudanças que ocorriam no mundo, até o fim da década de 1970 uma visão funcionalista prevaleceu na Administração de Recursos Humanos (ARH), segundo a qual as organizações buscaram técnicas, ferramentas e modelos para alcançar eficácia na gestão. O modelo organizacional de ARH predominante era o vertical e compartimentado (Hanashiro, 2007). Segundo essa visão funcionalista, os resultados desejados são alcançados na organização por meio das funções de atrair, selecionar, reter, incentivar, treinar, avaliar e remunerar. Essa visão intraorganizacional da estrutura por funções mostrou-se insuficiente. No início da década de 1980, a ARH ganha espaço enfatizando-se o alinhamento das políticas de pessoal aos objetivos estratégicos da organização e a transformação dos gestores de RH em consultores internos neste processo (Davel e Vergara, 2001). Na década de 1990, estudiosos da teoria organizacional creditam o sucesso de uma organização à implementação de formas flexíveis de gestão (Guimarães, 2000). Nesse período surge a aborda- 
gem da Administração Estratégica de Recursos Humanos (AERH), que focaliza a adaptabilidade e a flexibilidade como elementos precípuos. De acordo com Teixeira e Zacarelli (2007), os funcionários deixam de ser administrados como recursos e são percebidos e aceitos como seres em evolução capazes de gerar bem-estar e riqueza.

Um programa de modernização da administração pública que privilegie a abordagem da AERH e a implementação de ferramentas como DCO e programas motivacionais fundamentados nesses diagnósticos sinaliza a valorização das pessoas nas organizações.

\section{Clima organizacional e motivação nas organizações}

Entende-se por clima organizacional o conjunto de percepções, conceitos e sentimentos que as pessoas compartilham a respeito da organização e que afetam, de maneira positiva ou negativa, a forma como as pessoas ou grupos se relacionam no ambiente de trabalho, seu comprometimento e desempenho (Souza, 1980). Autores como Davel e Vergara (2001) reconhecem que os integrantes de uma organização formal desenvolvem percepções subjetivas a respeito das propriedades objetivas desta organização, ou seja, desenvolvem sentimentos em relação às diversas variáveis que compõem a organização, como salários, instalações físicas, comportamento dos gestores, entre outras. Assim sendo, um DCO pode auxiliar os gestores da organização a perceber até que ponto suas práticas de gestão estimulam o interesse, a dedicação e a motivação das pessoas ao trabalho.

A palavra motivação indica o processo pelo qual um conjunto de razões ou motivos explica, induz, incentiva, estimula ou provoca algum tipo de ação ou comportamento humano. De acordo com Vergara (1999:41), trata-se de um processo, "Motivação não é um produto acabado; antes, um processo que se configura a cada momento, no fluxo permanente da vida". O caráter singular da motivação é também apontado por Vergara (1999:42), "[a motivação] nos é, absolutamente, intrínseca, isto é, está dentro de nós, nasce de nossas necessidades interiores". Antes, Bergamini (1997) distinguira a motivação extrínseca da intrínseca, apontando que durante muito tempo se confundiu "pura reação" (condicionamento) com "motivação autêntica".

Portanto, quando se focaliza o trabalho realizado nas organizações e se reconhece que o desempenho depende da motivação, a compreensão dos mecanismos da motivação no trabalho parece ser importante para o entendimento das razões ou motivos que influenciam o desempenho das pessoas. 
De acordo com Gutierrez (1988), Abraham Maslow, na década de 1950, desenvolveu uma teoria na qual descreveu e classificou necessidades humanas em cinco categorias hierárquicas: necessidades fisiológicas, de segurança, de participação, de autoestima e autorrealização. A busca para satisfazer suas necessidades motivaria o indivíduo a tomar uma direção e, somente depois de satisfeita uma das necessidades hierarquicamente inferior ou primária, o indivíduo procuraria satisfazer outras necessidades. Aprofundando, McClelland, apud Gutierrez (1988), diferenciou as necessidades dos motivos humanos por considerar que as necessidades são infinitas, o que obrigaria cada indivíduo a selecionar aquelas nas quais depositará sua energia, constituindo-se, assim, em seus motivos. Este pesquisador distinguiu três tipos de motivos sociais: poder, afiliação e realização.

O motivo "poder" se caracteriza pelo desejo de exercer influência e impacto sobre os outros. O motivo "afiliação" corresponde à necessidade de afeto, ou seja, pressupõe a necessidade de o indivíduo manter relações interpessoais estreitas com os demais. O motivo "realização" distingue os indivíduos pela sua necessidade de procurar alcançar sua autorrealização através da tarefa. O mesmo autor considera que um programa motivacional fundamentado na especificidade da realidade organizacional pode ser delineado uma vez que sejam identificados os motivos sociais dos indivíduos.

Estudos motivacionais e pesquisas de clima em organizações públicas como os de Souza $(1980 ; 1982)$ e de Gutierrez (1988) esclareceram a realidade no setor público e no privado. Gutierrez (1988) acredita que, se o clima organizacional estiver propício à satisfação das necessidades de seus membros, a eficiência da organização pode ser aumentada. Desta forma, apontou para a forte ligação entre o clima organizacional e a motivação dos seus membros, assim como para a necessidade de considerar as subculturas que integram a cultura organizacional. Assim, necessidades e motivos individuais formam o ambiente de trabalho (clima) e compõem sua cultura organizacional.

\section{Cultura organizacional e traços culturais brasileiros}

Denomina-se cultura o conjunto de crenças, atitudes e valores compartilhados pelo grupo e que orientam suas ações. Assim, o exame das práticas quotidianas permite perceber a cultura organizacional. Interpretar a cultura organizacional no quotidiano, identificando valores e comportamentos compartilhados pelos seus indivíduos, pode orientar os gestores sobre aspectos críticos para iniciar uma mudança organizacional possível (Freitas, 1997). No Brasil, de 
acordo com Vieira e colaboradores (2002), crenças e valores da cultura brasileira não só definem o escopo do relacionamento das organizações com o mercado, como também influenciam o desenvolvimento de processos e práticas de gestão nessas organizações. A capacidade de comunicação da cultura é reconhecida por Motta e Caldas (1997:27): "antes de mais nada a cultura é linguagem, é código", ou seja, por meio desses códigos os atores organizacionais percebem e transmitem aos novos sua cultura organizacional.

\section{Traços culturais brasileiros na administração pública}

Os traços culturais brasileiros foram originados com base em diversas etnias e costumes (Freitas, 1997; Motta e Caldas, 1997; Motta e Alcadipani, 1999). Na cultura brasileira "plural, complexa e multifacetada" (Caldas, 1997:81), raízes diversas formam o "pano de fundo" para a compreensão desses traços que "representam aqueles pressupostos básicos que cada indivíduo usa para enxergar a si mesmo como brasileiro" (Freitas, 1997:39). Entre os traços brasileiros identificados por Holanda (1971), Freyre (1984), Da Matta (1997) e Motta e Caldas (1997) destacam-se sete: o formalismo, o pessoalismo, a valorização das relações, a aversão à incerteza, a flexibilidade, a orientação para o curto prazo e o estrangeirismo. Para Freitas (1997:54), os traços culturais brasileiros são ambíguos, "somos a sociedade da mistura, do intermediário, do mulato". Assim, traços culturais podem facilitar ou inibir mudança organizacional.

Desse modo, a adesão à mudança só parece viável quando os pressupostos, valores, crenças da organização são conjuntamente considerados, e para uma gestão do setor público também parece necessário desvendar os traços culturais brasileiros.

O brasileiro foi caracterizado como homem "cordial" por Da Matta, de acordo com Vieira e colaboradores (2002:6), em virtude da predominância do conteúdo emocional na cultura, "[o homem cordial] manifesta sua aversão a qualquer tipo de ritualismos e somente aceita relações sociais com base pessoal". Por isso, um individualismo com o consequente descaso por ideais comunitários e uma busca de prazeres de curto prazo caracterizam o "homem cordial" brasileiro. A atuação do homem "cordial" se opõe ao comportamento esperado do homem "racional" numa organização burocrática, onde deve funcionar numa hierarquia bem definida de autoridade, com divisão do trabalho fundamentada em especialização funcional, regras e procedimentos formais, impessoalidade e seleção com base na competência. Assim, dois traços cultu- 
rais caracterizam esse "homem cordial": "o autoritarismo com centralização" das decisões organizacionais e "o pessoalismo" nas relações interpessoais.

O autoritarismo se manifesta em situações onde há divisão de poder, tais como nas relações superior-subordinado e na centralização de decisões. O pessoalismo originou-se da imposição da industrialização para que o brasileiro faça a distinção entre "pessoa" e "indivíduo". Nas organizações burocráticas brasileiras, a impessoalidade no relacionamento pretende ser preservada pela formalização e pelo dever de aplicar regras. No entanto, o tratamento impessoal termina por ceder aos laços de amizade, propiciando que as relações entre o superior e o subordinado assumam caráter pessoal. Desse modo, o pessoalismo enfraquece o poder de controle das leis burocráticas e o tratamento impessoal acaba rejeitado (Rodrigues e Sá, 1984).

Em estudo empírico sobre a aplicação de outra ferramenta de gestão: a avaliação de desempenho no Poder Judiciário, Narducci e colaboradores (2006) identificaram a mútua influência entre três ações dos serventuários associadas aos traços culturais brasileiros manifestos diante da iminência da aplicação da lei ou regulamento, como no caso da modernização da administração pública: a) autoritarismo ou revelação ostensiva da própria identidade; b) pessoalismo, isto é, o recurso da amizade; e c) formalismo junto com a prática do "jeitinho" brasileiro.

O "jeitinho" brasileiro, segundo Motta e Alcadipani (1999), constitui um mecanismo de controle social socialmente construído que funciona pela competição, pela busca do sucesso (econômico) e pela busca de afiliação (reconhecimento) entre os membros da organização. O "jeitinho" seria um traço cultural que faz com que, perante uma situação difícil, o brasileiro espere "dar um jeito" para resolvê-la, ou seja, "driblar" determinações. Os autores explicam um recurso ao "jeitinho", denominado "operação-padrão", que ocorre "quando os funcionários de uma organização decidem realizar suas tarefas seguindo fielmente as normas preestabelecidas para aquela função, ou seja, seguindo a normatização à risca" (Motta e Alcadipani, 1999:10).

A pessoalidade ou pessoalismo, isto é, o valor que é pessoalmente atribuído à pessoa também explica o recurso ao "jeitinho", pois os interesses pessoais são percebidos como mais importantes do que os do conjunto da sociedade. Já o autoritarismo, refletido na frase "Você sabe com que está falando?", embora oposta à simpatia e humildade do "homem cordial" brasileiro, decorre também do "jeitinho", visto que essa frase é comumente usada por alguém que se sente hierarquicamente superior e acredita, por isso, estar "habilitado" a infringir uma norma para atingir um objetivo. Essa frase pretende deixar claras as diferenças de status na sociedade brasileira (Motta e Alcadipani, 1999). 
Em estudo mais recente, Alcadipani e Crubellate (2003) associaram quatro traços brasileiros a quatro ações individuais e configuraram quatro formas de ação (estratégias) da cultura brasileira que, acreditam, devem ser alteradas para implementar uma mudança efetiva da cultura. São elas: o formalismo, a flexibilidade, a lealdade às pessoas e o paternalismo. Essas estratégias dão lugar a quatro subsistemas de ação: dois por parte dos líderes, a) concentração de poder; b) pessoalismo, e dois por parte dos liderados, c) postura de espectador; d) de evitar conflitos. Assim, esses autores reconhecem que na gestão de organizações públicas os traços culturais brasileiros e os valores organizacionais coexistem com as características e estruturas da administração pública burocrático-tradicional.

Para Misocsky (2002), as estruturas organizacionais dos três níveis de governo no Brasil se apresentam com formato piramidal, composto de escalões hierárquicos organizados funcionalmente. Nesta conjuntura, as práticas de trabalho apresentam-se centralizadas e com excesso de formalização, o que acaba por provocar um grande distanciamento entre a organização e o cidadão-usuário. Entretanto, para essa autora, o modelo de gestão na administração pública brasileira se torna mais complexo porque estas características da burocracia tradicional se apresentam mediadas pela especificidade de sua cultura e subculturas organizacionais.

Nas intervenções para modernizar o Estado e profissionalizar a gestão pública, Paula (2005) considera que a vertente gerencialista ou APG tem predominado efetivamente sobre a prática de uma administração burocrática tradicional weberiana.

\section{O modelo de Administração Pública Gerencial (APG): contribuições e limites}

A discussão sobre a Reforma Gerencial do Estado no Brasil, de acordo com Bresser-Pereira e Spink (1998), se intensificou a partir da década de 1990, porque o modelo burocrático era "lento, caro e ineficiente", não atendia às demandas da sociedade. Seu principal objetivo foi flexibilizar os processos burocráticos para atender uma sociedade insatisfeita com os serviços públicos prestados no Brasil. Bresser-Pereira e Spink (1998) afirmaram que o modelo de APG transformaria duas dimensões: a) a cultura burocrática do Estado em uma cultura gerencial e b) a gestão, onde os administradores colocariam em prática ideias e ferramentas de gestão utilizadas no setor privado, adaptadas ao setor público. 
A APG, considerada como um grande avanço na gestão pública, surge com a orientação de atender ao cidadão cujos direitos ultrapassavam os direitos de um cliente ou consumidor. A APG fora definida em 1995 no Plano Diretor da Reforma do Estado e viabilizada após promulgação da emenda constitucional de 1998. Segundo esse plano diretor, além de se reorganizar o aparelho do Estado e fortalecer seu núcleo estratégico, a APG realizaria a transformação do modelo de administração pública vigente de modo a atender a demanda da sociedade (Abrucio, 1997; Pacheco, 2002). Entretanto, Abrucio (1997) considera a APG "neotaylorista", por privilegiar apenas a busca pela produtividade.

Em recente estudo, Paula (2005a) caracterizou, reconheceu contribuições e apontou limites da Administração Pública Gerencial no alcance da efetividade na sociedade e defendeu uma Administração Pública Societal (APS). Essa autora considera a APG, iniciada em 1980, um movimento para reforma do Estado que implementou um modelo de gestão pública inspirado no design sugerido pelo movimento internacional com base nos modelos inglês e estadunidense. A APG, de acordo com Paula (2005a): a) enfatiza a eficiência administrativa e se baseia no ajuste estrutural, nas recomendações dos organismos multilaterais internacionais e no movimento gerencialista; b) enfatiza as dimensões econômico-financeira e institucional-administrativa deixando de lado a dimensão sociopolítica; c) enfatiza o gerencialismo como abordagem de gestão e a adaptação dos modelos gerencialistas para o setor público; d) separa as atividades exclusivas das não exclusivas do Estado nos três níveis governamentais; e) apresenta um discurso participativo, mas centraliza o processo decisório, a organização das instituições e a construção de canais de participação popular.

Paula (2005a) também apontou três limites da APG: a) mais ênfase nas dimensões estruturais do que nas dimensões sociais e políticas da gestão; b) não apresentação de uma proposta nova para a organização do aparelho do Estado; c) centralização do processo decisório e não estímulo a instituições políticas mais abertas à participação social. No entanto, reconheceu-lhe duas contribuições: a) clareza em relação à organização do aparelho do Estado e métodos de gestão; b) melhoria da eficiência do setor público, especialmente no campo econômico-financeiro, pela utilização de alguns de seus métodos.

Por ser o gerencialismo de origem estrangeira, a influência da cultura brasileira em instituições públicas deve ser reconhecida quando se pretende seguir um modelo de APG (Abrucio, 1997; Vieira et al., 2002). Esses autores reconhecem dimensões além das formais e objetivas nas organizações, afirmando a importância da utilização da perspectiva cultural como forma de 
resgatar a subjetividade existente nas respostas que são oferecidas pela organização aos problemas operacionais e institucionais com que se defrontam.

Com o entendimento conceitual que considera a inter-relação da cultura organizacional brasileira com a administração pública, em suas duas vertentes — burocrático tradicional e gerencial —, identificaram-se os traços revelados no Tribunal Regional de Justiça.

\section{Estudo de caso no Poder Judiciário}

A modernização da gestão do Poder Judiciário, iniciada em 2001 com a Reforma do Estado, previa a elaboração de uma metodologia para DCO cujos resultados por sua vez conduziriam a um programa motivacional específico para as unidades desse Tribunal Regional de Justiça. No presente estudo foram considerados os sete fatores de clima organizacional associados aos três tipos de motivos sociais do indivíduo propostos por McClelland, examinados por Gutierrez (1988:7) e Souza (1980):

\section{Quadro 1}

Fatores constitutivos do clima associados aos motivos sociais para o trabalho

\begin{tabular}{|c|c|}
\hline Sete fatores do clima organizacional & Três motivos sociais dos indivíduos \\
\hline V Trabalho em equipe & V Afiliação \\
\hline V Recompensa & V Afiliação \\
\hline V Confiança e apoio interpessoal & V Afiliação \\
\hline v Autonomia & v Poder \\
\hline v Liderança & V Poder \\
\hline V Padrões de desempenho individual & v Realização \\
\hline v Clareza organizacional & V Realização \\
\hline
\end{tabular}

Fonte: Souza (1980; 1982) e Gutierrez (1988) com adaptações.

Três traços culturais brasileiros inter-relacionados se manifestaram desde a fase exploratória, quando foram realizadas as primeiras entrevistas com gestores desse Tribunal Regional de Justiça: autoritarismo, pessoalismo e centralização decisória.

O autoritarismo revelou-se em função do reconhecimento da identidade do juiz na percepção dos entrevistados: "o juiz se recolhe e, pela natureza de 
sua função, entra em contato com Deus para interpretar e decidir as sentenças" (gestor: juiz). O juiz é percebido também pelos serventuários entrevistados não apenas como representante do Estado, mas como sendo o próprio Estado e esta ideia se manifestou, por exemplo, quando se referiram ao uso da toga:

O Juiz pode ser democrático durante o trabalho com sua equipe, mas quando coloca a toga sinaliza que tudo que for a ele manifestado está sendo dito não ao indivíduo, mas ao Estado diretamente. Por isso pode te dar voz de prisão se considerar-se desacatado. Afinal trata-se de um desacato ao Estado, não ao indivíduo apenas (gestor: serventuário).

O pessoalismo foi sinalizado ao solicitar-se explicação sobre as diferenças no ambiente de trabalho nos diversos setores como o protocolo, as varas, com os que trabalham em gabinete. Revelou-se a autonomia e o pessoalismo do juiz para escolher sua equipe: "[...] [quando indico quem trabalha no Gabinete] ninguém pode me impor sentir confiança por alguém por mais capacitado profissionalmente que seja para trabalhar perto de mim, só eu decido em quem confio e em quem não confio" (gestor: juiz).

Já os serventuários que são transferidos para o setor de protocolo são os considerados problemáticos, "que não deram certo em outros setores".

A centralização das decisões foi percebida também pelo consenso dos entrevistados quanto à descontinuidade na gestão e à dependência de cada novo presidente para levar adiante as iniciativas de melhoria do serviço público: "O Presidente eleito deve dar continuidade sim [...], mas já houve caso de o novo Presidente não dar continuidade e aí, não tem jeito [...]” (gestor: serventuário).

Considerando estes traços culturais manifestados nas entrevistas, configurou-se uma metodologia para DCO pertinente a essa realidade organizacional.

\section{A concepção da metodologia para diagnóstico de clima organizacional (DCO)}

De acordo com a "missão" e os objetivos estabelecidos neste Tribunal Regional, era necessário que a proposta de uma metodologia para DCO considerasse o estudo dos fatores específicos influenciadores do clima organizacional para subsidiar uma proposta de programa motivacional para o tribunal. O quadro 2 apresenta o plano de trabalho elaborado. 


\section{Quadro 2 \\ Plano de trabalho para concepção da metodologia de DCO}

1. anamnese, isto é, trazer de volta à mente os fatos relacionados à problemática; recordar com os responsáveis solicitantes;

2. configuração da situação: problema pela identificação de sintomas e possíveis efeitos;

3. Estabelecimento de objetivos (geral e intermediários) e delimitação do diagnóstico de clima e do programa motivacional;

4. identificação e seleção do universo, população e amostra para pesquisa qualitativa exploratória;

5. criação das ferramentas de coleta de dados (roteiro para entrevista em profundidade prévia caracterização da organização/área sob estudo);

6. tabulação, análise e interpretação dos dados qualitativos;

7. elaboração de relatório com resultados da(s) entrevista(s) exploratória(s);

8. elaboração de questionário(s) para diagnóstico de clima organizacional no tribunal;

9. determinação da amostra para aplicação: piloto do questionário diagnóstico de clima;

10. aplicação do piloto do questionário para diagnóstico de clima organizacional na amostra escolhida;

11. tabulação e análise dos resultados do piloto;

12. elaboração de relatório;

13. aplicação de questionário modificado à população selecionada (pesquisa extensiva);

14. tabulação e análise dos dados;

15. elaboração de relatório dos resultados de campo;

16. elaboração das conclusões sobre o diagnóstico de clima organizacional no TRT e recomendações para programa motivacional (conteúdo e estratégia de realização).

Fonte: Elaboração própria.

Paralelamente, selecionaram-se sete fatores de clima e três motivações conforme o quadro 1 e foram entrevistados os "gestores líderes" desse tribunal: desembargadores, juízes e serventuários que ocupavam cargos cujas funções incluíam gerir pessoas.

Nas entrevistas utilizou-se um roteiro semiestruturado visando levantar com os gestores sua percepção sobre o objetivo de uma pesquisa de clima e seu entendimento sobre o clima organizacional atual do Tribunal Regional de Justiça. Também procurou-se levantar as trajetórias acadêmicas e profissionais e indagar sobre as dimensões do trabalho que, na percepção desses gestores, mais afetavam as inter-relações de suas equipes, assim como as possíveis 
causas da "desmotivação" para o trabalho dos serventuários sob sua responsabilidade. Os dados levantados nestas entrevistas foram qualitativamente interpretados, considerando também os dados documentais sobre "atribuições" e a "estrutura organizacional" vigentes nesse tribunal.

Após a análise das respostas iniciais, foi elaborado um questionário com nove questões mais próximas dessa realidade que, depois de validado semanticamente pelos oito gestores do tribunal entrevistados, foi aplicado como projeto-piloto para evidenciar alterações necessárias ao "questionário modificado" que, em fase posterior, será extensivo a todo Tribunal Regional de Justiça. A seguir descreve-se o processo de sua elaboração e ao final da seção apresenta-se na figura 4 o "questionário modificado".

No projeto-piloto, as primeiras sete questões resultaram da associação de sete fatores do ambiente de trabalho com três motivos sociais considerados pertinentes a este tribunal. A oitava questão solicitou que os respondentes escolhessem apenas três fatores mais importantes, e a nona questão, aberta, pediu que mencionassem outros fatores de clima diferentes dos considerados no questionário. As perguntas do questionário foram inicialmente respondidas numa escala de 10 pontos do tipo Likert para duas dimensões, uma associada à "situação real" e a outra à "situação ideal" para cada fator, e uma terceira dimensão, "importância", para apurar a importância atribuída ao conjunto de fatores de clima organizacional. O uso da escala de Likert no questionário foi bem avaliado, "[uma escala quantitativa] confere mais objetividade ao estudo" (gestor: juiz).

O projeto-piloto foi aplicado a 42 serventuários lotados em três setores (1 $1^{\mathrm{a}}$ vara, 26a vara e Secretaria de Orçamento e Finanças - SOF), que formaram uma amostra por conveniência. Não se solicitou a identificação do respondente e o preenchimento do questionário ocorreu sem a intervenção do pesquisador ou gestor no processo. Disponibilizou-se uma equipe previamente treinada para auxiliar o respondente por telefone, caso ocorressem dúvidas. Quarenta questionários preenchidos foram devolvidos em sete dias, os dois não devolvidos eram de respondentes que entraram em férias no período da aplicação.

No período de observação direta desta pesquisa se percebeu a coexistência de serventuários promovidos a cargos de gestão pelo tempo de casa no Tribunal Regional de Justiça com os serventuários concursados, com os concursados formados em administração e com os que, por iniciativa própria, haviam investido em sua formação gerencial. Ressalta-se que alguns desses serventuários já haviam atuado na iniciativa privada e fizeram concurso público para alcançar a estabilidade trabalhista. No momento atuavam, fora do serviço público, como docentes horistas em faculdades particulares. 
Realizou-se uma análise quantitativa descritiva dos dados coletados por meio de questionário no projeto-piloto, na qual foram calculados os valores médios atribuídos a cada um dos sete fatores de clima e agregados aos motivos sociais de "realização", "afiliação" e "poder".

O questionário para DCO solicitava a avaliação dos respondentes sobre a intensidade da presença de sete fatores de clima numa escala de 1 ("não está presente") a 10 ("está presente sempre"). Perguntou-se, também, separadamente, sobre a importância desses sete fatores e, em uma questão aberta, sobre outros fatores de clima não mencionados no questionário. Os sete fatores foram avaliados no nível ideal ("existência desejada do fator") e no nível real ("existência percebida desse fator"). Também calculou-se a amplitude entre o ideal e o real segundo os respondentes, com a finalidade de entender a distância entre o esperado e o efetivamente percebido.

Nessa análise do projeto-piloto foi possível observar, como ilustrado na figura 1, que: a) as médias atribuídas aos fatores de clima na situação ideal apresentaram três grupos. Em um primeiro grupo, as maiores médias foram dadas para o fator "trabalho em equipe", seguido dos fatores "clareza organizacional", "confiança e apoio interpessoal" e "liderança". Em um segundo grupo, com menor média, aparecem "recompensa" e "padrões de desempenho". O fator "autonomia", que corresponde ao motivo social "poder", aparece em um terceiro grupo com a menor média no nível "ideal". Neste caso, os dados indicam que a necessidade de poder, que fundamenta o motivo social de poder, seria menos desejada que as de afiliação e de realização.

Quando se analisam as respostas no nível "real" (o percebido), ainda na figura 1, observam-se também três grupos onde a maior média foi alcançada pelo fator "confiança e apoio interpessoal" (afiliação). Em um segundo grupo, com menor intensidade, seguem os fatores "trabalho em equipe" (afiliação) e "liderança" (poder). No terceiro grupo, com as menores médias atribuídas, encontram-se os fatores "padrões de desempenho individual" (realização) e "recompensa" (afiliação). Deste modo, os respondentes indicaram a necessidade de "recompensa" como menos atendida nesse ambiente de trabalho, sugerindo que o motivo social de afiliação deveria ser mais atendido.

Quando observada a diferença percentual entre os fatores, percebem-se três grupos onde o fator "recompensa" (afiliação) apresenta a maior diferença. O segundo grupo com menos diferença corresponde aos fatores "padrões de desempenho individual" (realização) e "clareza organizacional" (realização) e o terceiro grupo com menor diferença é formado pelos fatores "liderança" (poder), "trabalho em equipe" (afiliação), "autonomia" (poder) e "confiança e apoio interpessoal" (afiliação). 
Considerando as respostas à oitava questão, embora o fator "recompensa" apareça como o de maior diferença percentual, este havia sido avaliado como o sexto no "real" e o quarto na situação "ideal". Por isso, parece que o motivo social realização, muito embora composto pelos fatores do segundo grupo, deve ser atendido antes que os motivos de afiliação e poder.

\section{Figura 1}

Médias calculadas para cada atribuição (valor real ou ideal) dos fatores com a diferença percentual dos fatores e seus respectivos motivos sociais

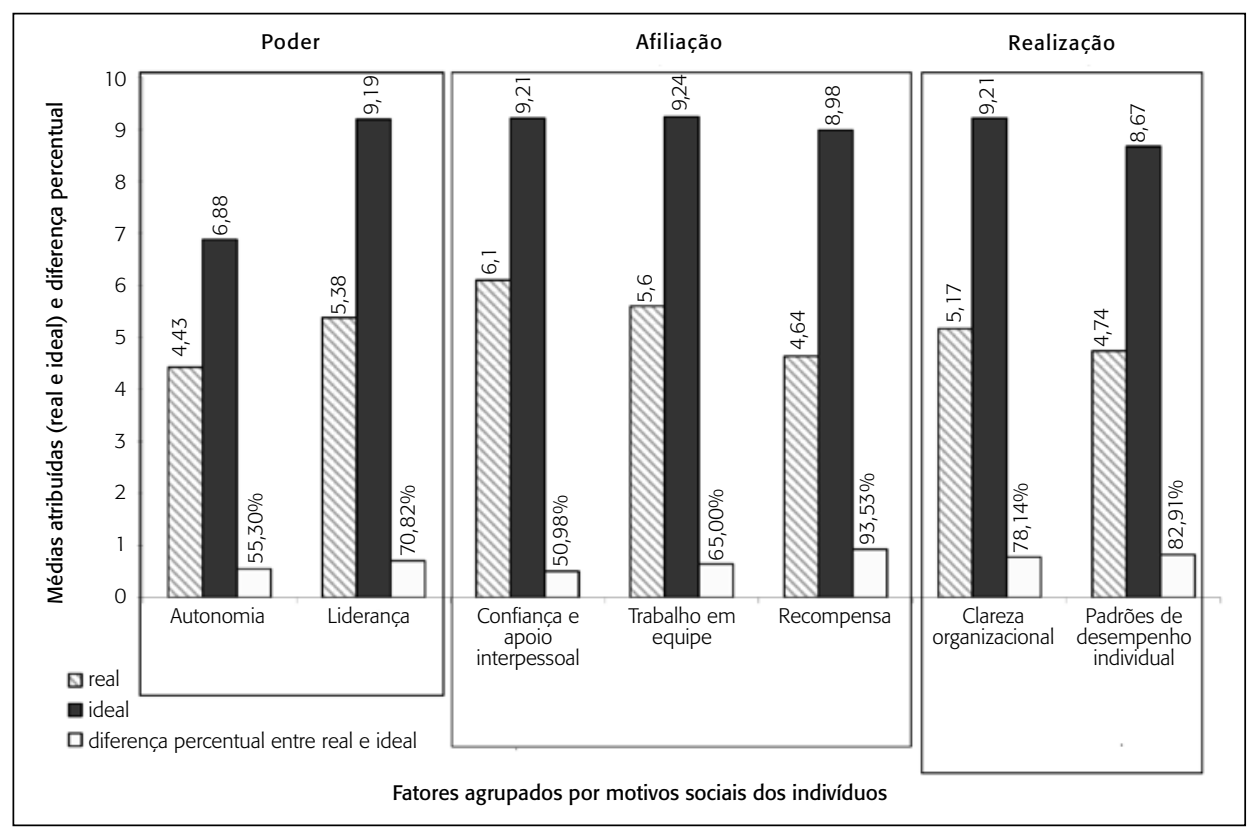

Fonte: Elaboração própria com base nos resultados do projeto-piloto.

Em um ambiente de trabalho marcado por traços de autoritarismo, centralização e pessoalismo, onde as hierarquias e fontes de poder formal são princípios aceitos, parece pertinente que o ambiente de trabalho deva propiciar a realização dos serventuários antes mesmo do motivo social "afiliação", visto que parece haver conformidade com as diferenças. Neste sentido, nem as identidades profissionais dos juízes e nem as dos serventuários foram postas em discussão.

Na figura 2 destaca-se que a amplitude média maior entre o fator de clima real e ideal corresponde ao fator "recompensa" (afiliação), indicando 
que este fator apresenta-se como o mais deficiente, segundo os respondentes. Pode-se dar destaque também a dois fatores que apresentaram uma amplitude média menor: "autonomia" (poder) e "confiança e apoio interpessoal" (afiliação). Mostrando, assim, que estes fatores seriam menos críticos na percepção dos respondentes.

Figura 2

Médias das amplitudes (diferença entre real e ideal, valores absolutos) por fator

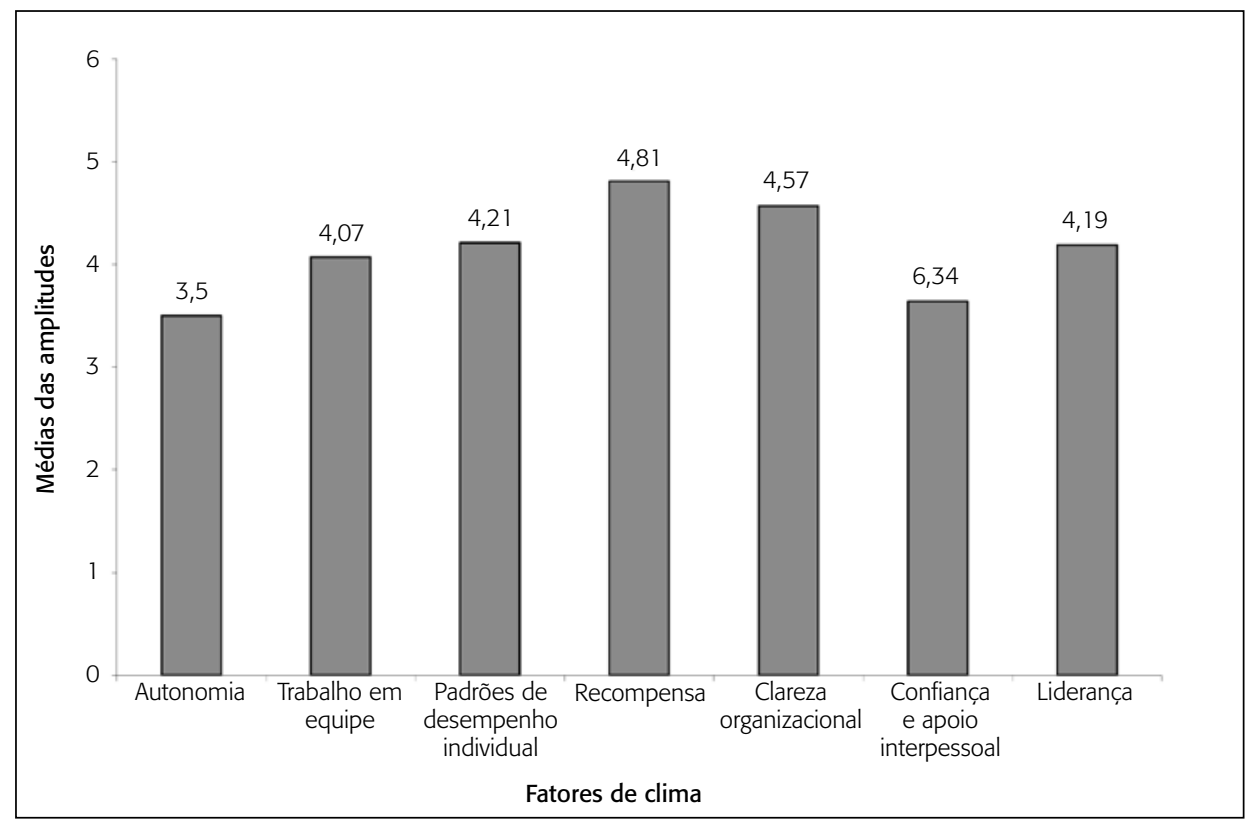

Fonte: Elaboração própria com base nos resultados do projeto-piloto.

A seguir, na figura 3, apresentam-se os resultados da questão oito, na qual a maior importância foi atribuída ao fator "trabalho em equipe" (afiliação), seguido de "padrões de desempenho", "clareza organizacional" (realização) e "liderança" (poder). Em menor escala de importância encontram-se três fatores: "recompensa", "confiança e apoio interpessoal" e "autonomia", sinalizando que como o fator "trabalho em equipe", questionado na segunda questão, fora percebido como o segundo mais presente, os motivos afiliação e poder podem ser atendidos após a consideração do motivo de realização num futuro programa motivacional. Ressalta-se que estas observações foram realizadas com base no projeto-piloto. 
Figura 3

Frequência dos fatores de clima organizacional e sua importância

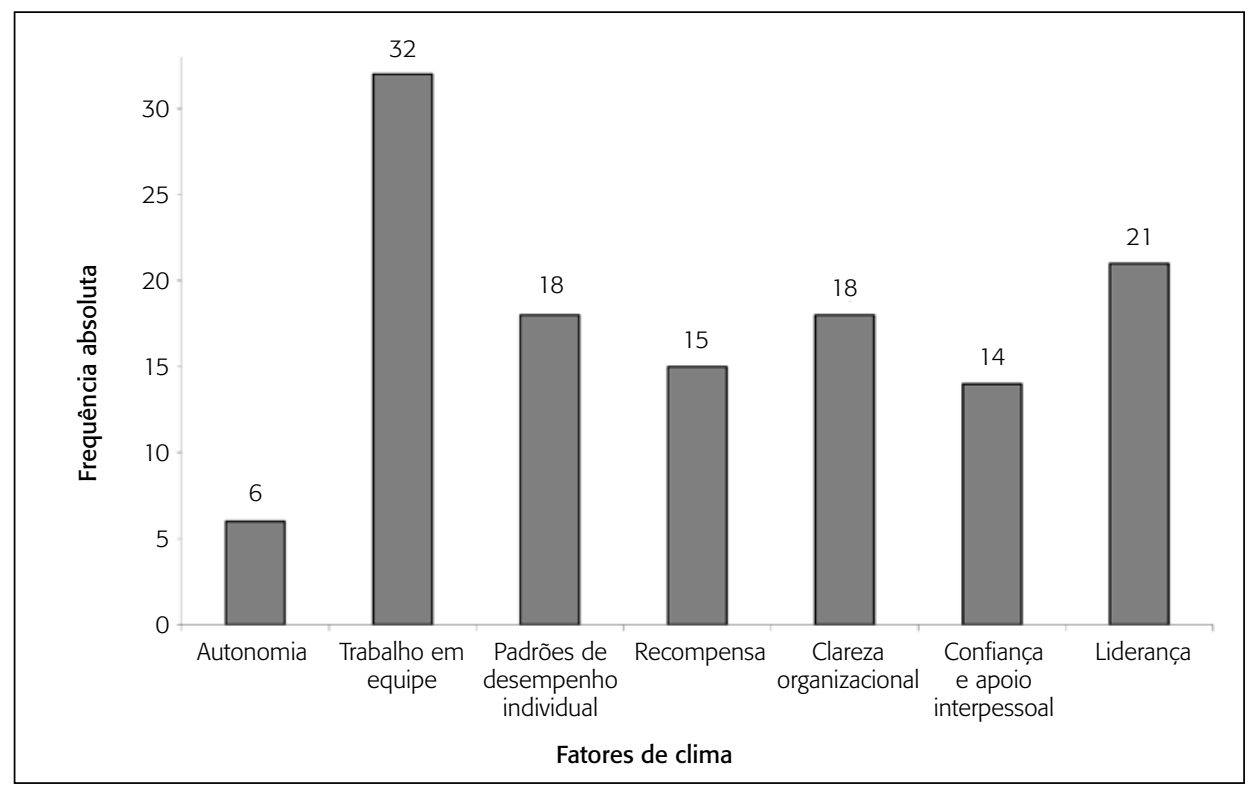

Fonte: Elaboração própria com base nos resultados do projeto-piloto.

\section{Observações para os ajustes finais no questionário de DCO}

Com base nos resultados da aplicação do projeto-piloto elaboraram-se recomendações para a construção do denominado "Questionário modificado para DCO", apresentado na figura 4, a ser aplicado em todo o Tribunal Regional de Justiça:

a) incluir em cada questão uma terceira escala sobre o grau de "importância" juntamente com as escalas do "real" e do "ideal", e não em questão específica como realizado no projeto-piloto. Este ajuste possibilitaria a análise da correlação de duas variáveis: amplitude entre o "real", o "ideal" e a "importância" atribuída por cada respondente. Além disso, os dados propiciariam parametrizar uma terceira dimensão de escala, na qual seria possível medir quantidade, qualidade e intensidade dos fatores de clima organizacional, ou seja, quantificar a subjetividade da ferramenta DCO;

b) utilizar uma escala Likert de apenas seis pontos, pois a escala de dez pontos com duas dimensões foi criticada no projeto-piloto por dificultar o processo de mensuração em cada pergunta; 
c) acrescentar no questionário mais uma pergunta relacionada ao motivo "poder", visando, assim, manter um equilíbrio ao perguntar sobre os motivos sociais que atuam nas pessoas (afiliação, poder e realização);

d) realizar amostragem aleatória estratificada por cargo e/ou por unidade geográfica, para possibilitar uma análise comparativa, por exemplo, análise da variância, análise multivariada, e minimizar o sentimento de vulnerabilidade e temor de retaliações manifestado pelos respondentes.

Figura 4

Questionário modificado para diagnóstico de clima organizacional

\begin{tabular}{|c|c|c|c|c|c|c|c|}
\hline \multicolumn{4}{|c|}{ DADOS GERAIS (opcional): Local de Trabalho } & \multicolumn{3}{|c|}{ Unidade } & otação \\
\hline \multicolumn{8}{|c|}{ INSTRUÇÕES } \\
\hline \multicolumn{8}{|c|}{$\begin{array}{l}\text { O Tribunal, dentro do seu foco estratégico "Valorizar Magistrados e Serventuários", está realizando } \\
\text { uma pesquisa de clima organizacional (PCO) com o objetivo de coletar a sua percepção a } \\
\text { respeito do setor onde atua no Tribunal. A finalidade dessa pesquisa é subsidiar o aprimoramento } \\
\text { de processos específicos de gestão de pessoas que contribua para a melhoria do ambiente de } \\
\text { trabalho. Assim, a sua participação, por meio do preenchimento deste questionário, é muito } \\
\text { importante para todos. } \\
\text { Seguem dez questões para sua avaliação. Antes de cada requadro, encontrará uma definição } \\
\text { geral para cada fator, que deverá ser considerada ao responder sobre as afirmações dos } \\
\text { requadros. Entretanto, lembre-se que a avaliação solicitada refere-se a sua experiência no setor } \\
\text { onde atualmente está lotado no Tribunal. Portanto, responda segundo sua percepção e em } \\
\text { relação a seu setor de atuação. As afirmações que avaliará se encontram em pares à direita e à } \\
\text { esquerda de cada escala de graduação (de } 1 \text { a } 6 \text { ). Por favor, avalie cada par de afirmações de } \\
\text { cada requadro primeiro em três aspectos: sobre a situação real, depois sobre a situação ideal e, } \\
\text { por fim, sobre a importância do fator no ambiente de trabalho. }\end{array}$} \\
\hline \multicolumn{8}{|c|}{ QUESTÕES } \\
\hline \multicolumn{8}{|c|}{$\begin{array}{l}\text { Q1. Conformidade com as normas: sentimento de que existem regras, procedimentos, diretrizes } \\
\text { e práticas administrativas que têm de ser seguidos embora tirem a liberdade de fazer o trabalho } \\
\text { da forma mais adequada. }\end{array}$} \\
\hline $\begin{array}{r}\text { Conformidade não é uma } \\
\text { característica na minha unidade } \\
\text { no Tribunal }\end{array}$ & 1 & 2 & 3 & 4 & 5 & 6 & $\begin{array}{l}\text { Conformidade é uma } \\
\text { característica muito presente na } \\
\text { minha unidade no Tribunal. }\end{array}$ \\
\hline \multicolumn{8}{|l|}{ Real } \\
\hline \multicolumn{8}{|l|}{ Ideal } \\
\hline Importância & & & & & & & \\
\hline
\end{tabular}

Continua 
Q2. Trabalho em equipe: sentimento de que a integração facilita o cumprimento dos objetivos propostos pela organização. O sentimento de que as áreas, os indivíduos e os grupos (setores) trabalham de forma complementar para o alcance dos objetivos da organização.

\begin{tabular}{|r|l|l|l|l|l|l|l|}
\hline $\begin{array}{r}\text { Não existe trabalho em equipe } \\
\text { na minha unidade no Tribunal }\end{array}$ & 1 & 2 & 3 & 4 & 5 & 6 & $\begin{array}{l}\text { Existe forte ênfase no trabalho em } \\
\text { equipe na minha unidade no Tribunal }\end{array}$ \\
\hline Real & & & & & & & \\
\hline Ideal & & & & & & & \\
\hline Importância & & & & & & & \\
\hline
\end{tabular}

Q3. Padrões de desempenho: sentimento de que na organização enfatiza-se o desempenho com qualidade e produtividade superiores, inclusive estabelecendo metas estimulantes para si mesma e transmitindo às pessoas a importância do comprometimento com estas metas.

\begin{tabular}{|c|c|c|c|c|c|c|c|}
\hline $\begin{array}{r}\text { Os padrões de desempenho do } \\
\text { meu setor no Tribunal são muito } \\
\text { baixos e não existem metas } \\
\text { desafiadoras }\end{array}$ & 1 & 2 & 3 & 4 & 5 & 6 & $\begin{array}{l}\text { Os padrões de desempenho do } \\
\text { meu setor no Tribunal são muito } \\
\text { elevados com metas desafiadoras }\end{array}$ \\
\hline \multicolumn{8}{|l|}{ Real } \\
\hline \multicolumn{8}{|l|}{ Ideal } \\
\hline Importância & & & & & & & \\
\hline
\end{tabular}

Q4. Reconhecimento: sentimento de que as pessoas são reconhecidas e recompensadas por um bom trabalho e de que, quando algo sai errado, não são ignoradas, criticadas ou punidas.

\begin{tabular}{|r|l|l|l|l|l|l|l|}
\hline $\begin{array}{r}\text { As pessoas no meu setor no } \\
\text { Tribunal são ignoradas, punidas e } \\
\text { criticadas }\end{array}$ & 1 & 2 & 3 & 4 & 5 & 6 & $\begin{array}{l}\text { As pessoas no meu setor no } \\
\text { Tribunal são reconhecidas e } \\
\text { recompensadas }\end{array}$ \\
\hline Real & & & & & & & \\
\hline Ideal & & & & & & & \\
\hline Importância & & & & & & & \\
\hline
\end{tabular}

Q5. Clareza organizacional: sentimento de que os objetivos estão definidos claramente e são comunicados com transparência e de que não são desordenados, confusos ou nebulosos.

\begin{tabular}{|r|l|l|l|l|l|l|l|}
\hline $\begin{array}{r}\text { O trabalho no meu setor no } \\
\text { Tribunal é desordenado, confuso } \\
\text { ou nebuloso }\end{array}$ & 1 & 2 & 3 & 4 & 5 & 6 & $\begin{array}{l}\text { O meu setor no Tribunal é bem } \\
\text { organizado e com objetivos bem } \\
\text { definidos }\end{array}$ \\
\hline Real & & & & & & & \\
\hline Ideal & & & & & & & \\
\hline Importância & & & & & & & \\
\hline
\end{tabular}

Q6. Confiança e apoio interpessoal: sentimento de que a boa relação entre as pessoas (pares, subordinados e superiores hierárquicos) é valorizada; que as pessoas acreditam umas nas outras, 
respeitam e oferecem apoio uns aos outros. O sentimento de que boas relações profissionais para realizar o trabalho prevalecem entre as pessoas no ambiente de trabalho.

\begin{tabular}{|r|l|l|l|l|l|l|l|}
\hline $\begin{array}{r}\text { Não existe confiança nem apoio } \\
\text { interpessoal no trabalho no meu } \\
\text { setor no Tribunal }\end{array}$ & 1 & 2 & 3 & 4 & 5 & 6 & $\begin{array}{l}\text { Confiança e apoio interpessoal no } \\
\text { trabalho são características muito } \\
\text { presentes no meu setor no Tribunal }\end{array}$ \\
\hline Real & & & & & & & \\
\hline Ideal & & & & & & & \\
\hline Importância & & & & & & & \\
\hline
\end{tabular}

Q7. Liderança: sentimento de que a organização não é dominada nem dependente de poucos indivíduos. Quando surge a necessidade de liderança, as pessoas se sentem em liberdade de aceitar papéis de liderança.

\begin{tabular}{|c|c|c|c|c|c|c|c|}
\hline $\begin{array}{r}\text { Não existe no meu setor no } \\
\text { Tribunal liberdade para aceitação } \\
\text { de papéis de liderança }\end{array}$ & 1 & 2 & 3 & 4 & 5 & 6 & $\begin{array}{l}\text { Existe no meu setor no Tribunal } \\
\text { liberdade para aceitação de papéis } \\
\text { de liderança }\end{array}$ \\
\hline Real & & & & & & & \\
\hline Ideal & & & & & & & \\
\hline Importância & & & & & & & \\
\hline
\end{tabular}

Q8. Formação gerencial: sentimento de que na organização a liderança é exercida por gestores previamente preparados para a atuação gerencial.

\begin{tabular}{|c|c|c|c|c|c|c|c|}
\hline $\begin{array}{r}\text { Não existe no meu setor no } \\
\text { Tribunal formação gerencial para } \\
\text { as lideranças }\end{array}$ & 1 & 2 & 3 & 4 & 5 & 6 & $\begin{array}{l}\text { Existe no meu setor no Tribunal } \\
\text { formação gerencial para as } \\
\text { lideranças }\end{array}$ \\
\hline \multicolumn{8}{|l|}{ Real } \\
\hline \multicolumn{8}{|l|}{ Ideal } \\
\hline Importância & & & & & & & \\
\hline
\end{tabular}

Q 9. Impacto do trabalho: sentimento de que na organização o trabalho realizado está efetivamente auxiliando e que está fazendo diferença.

\begin{tabular}{|r|l|l|l|l|l|l|l|}
\hline $\begin{array}{r}\text { O trabalho no meu setor no } \\
\text { Tribunal não auxilia a Justiça nem } \\
\text { faz diferença para a sociedade }\end{array}$ & 1 & 2 & 3 & 4 & 5 & 6 & $\begin{array}{l}\text { O trabalho realizado em meu } \\
\text { setor no Tribunal auxilia a Justiça } \\
\text { e faz diferença para a sociedade }\end{array}$ \\
\hline Real & & & & & & & \\
\hline Ideal & & & & & & & \\
\hline Importância & & & & & & & \\
\hline
\end{tabular}

Q10. Com base em sua experiência, você considera que existe algum fator não apontado neste questionário que afeta o clima organizacional do seu setor? Se sua resposta for afirmativa, por favor, descreva o fator a seguir ou utilize o verso da folha.

Fonte: elaboração própria com base nos resultados do projeto-piloto. 


\section{Considerações finais e recomendações}

A proposta de utilizar uma ferramenta quantitativa de gestão de pessoas denominada "Questionário para DCO" foi inovadora no Tribunal Regional de Justiça examinado, embora a APG se encontre em desenvolvimento desde 2001. Até então, a tarefa de manter a motivação dos serventuários era deixada sob a responsabilidade de cada superior imediato, ou o servidor desmotivado pedia transferência de setor.

A metodologia para DCO foi solicitada para atender o foco estratégico de "Valorização de Magistrados e Serventuários", contemplado no Programa de Modernização da Administração Pública. Entretanto, percebeu-se desequilíbrio entre autoridade e a responsabilidade da função de gestão de pessoas neste tribunal.

Por um lado, o setor responsável, denominado Secretaria de Gestão de Pessoas, ainda atuava em nível de unidade operacional, vinculada à Diretoria Geral de Coordenação Administrativa. Por outro lado, a Escola de Administração de Serventuários, na qual se capacitam os serventuários e os gestores com cursos de administração profissional, estava diretamente vinculada à Presidência do Tribunal.

Mesmo preliminarmente, foi possível perceber e evidenciar no Tribunal Regional de Justiça estudado que: nem a análise quantitativa e nem a aplicação das ferramentas de gestão se realizam pontualmente em espaços "neutros", mas em coletividades de pessoas cuja atuação explicita a indissociabilidade entre objetividade e subjetividade nessa organização.

Com base nos resultados do projeto-piloto realizado, foi possível propor mudanças necessárias para superar resistências iniciais manifestadas pelos serventuários públicos participantes e propiciar a implantação da ferramenta DCO para gestão de pessoas como solicitado. Recomenda-se, pois, investir na divulgação, no treinamento específico sobre a metodologia para DCO e na capacitação em gestão de conflitos interpessoais com a finalidade específica de:

a) propiciar a postura de atores do processo por meio de preparação prévia dos serventuários para condução da pesquisa DCO;

b) realizar treinamento que capacite tecnicamente os coordenadores da pesquisa para DCO;

c) informar claramente ao servidor o objetivo e a finalidade da pesquisa de DCO;

d) preparar o ambiente físico e a logística para receber os questionários considerando o tempo médio para seu preenchimento;

e) disponibilizar canais de comunicação e tirar dúvidas anonimamente. 
Para a continuidade da pesquisa, sugere-se levantar a percepção de serventuários não gestores, separando-os por grupos para distinguir os motivos sociais mais presentes entre os serventuários nomeados, os concursados e os terceirizados.

\section{Referências}

ABRUCIO, F.L. O impacto do modelo gerencial na administração pública: um breve estudo sobre a experiência internacional recente. Cadernos ENAP, Brasília, n. 10, p. 1-52, 1997.

ALCADIPANI, R.; CRUBELLATE, J.M. Cultura organizacional: generalizações improváveis e conceituações imprecisas. Revista de Administração de Empresas - RAE, São Paulo, v. 43, n. 2, p. 64-77, 2003.

BARDIN, L. Análise de conteúdo. Lisboa: Edições 70, 1977.

BERGAMINI, C.W. Motivação nas organizações. São Paulo: Atlas, 1997.

. A difícil gestão das motivações. In: WOOD JR., T. (Org.). Gestão empresarial. São Paulo: Atlas, 2002. p. 111-128.

BRESSER-PEREIRA, L.C.; SPINK, P. (Org.). Reforma do Estado e administração pública gerencial. Rio de Janeiro: FGV, 1998.

CALDAS, M.P. Santo de casa não faz milagre: condicionantes nacionais e implicações organizacionais da fixação brasileira pela figura do "estrangeiro". In: MOTTA, F.P.; CALDAS, M.P. (Org.). Cultura organizacional e cultura brasileira. São Paulo: Atlas, 1997. p. 73-93.

DA MATTA, R. A casa \& a rua. Rio de Janeiro: Rocco, 1997.

DAVEL, E.; VERGARA, S.C. (Org.). Gestão com pessoas e subjetividade. São Paulo: Atlas, 2001.

DEMO, P. Metodologia das ciências sociais. São Paulo: Atlas, 1989.

FREITAS, A.B. Traços brasileiros para uma análise organizacional. In: MOTTA, F. P.; CALDAS, M.P. (Org.). Cultura organizacional e cultura brasileira. São Paulo: Atlas, 1997. p. 38-54.

FREYRE, G. Casa-grande \& senzala. Rio de Janeiro: José Olympio, 1984.

GUIMARÃES, T. de A. A nova administração pública e a abordagem de competências. Revista de Administração Pública - RAP, Rio de Janeiro, v. 34, n. 3, p. 125-140, maio/jun. 2000. 
GUTIERREZ, L.H. Percepção do clima organizacional conforme o escalão hierárquico. Revista de Administração de Empresas - RAE, São Paulo, v. 28, n. 4, p. 5-13, out./dez. 1988.

HANASHIRO, D.M.M. Limpando os conceitos. In: HANASHIRO, D.M.M.; TEIXEIRA, M.L.M.; ZACARELLI, L.M. (Org.). Gestão do fator humano: uma visão baseada em stakeholders. São Paulo: Saraiva, 2007. p. 338-369.

HOLANDA, S.B. de. Raízes do Brasil. Rio de Janeiro: José Olympio, 1971.

MISOCSKY, M.C.A. Mudanças na administração municipal: possibilidades de uma formação político-organizacional. Revista de Administração Contemporânea - RAC. v. 6, n. 2, p. 99-122, 2002.

MOTTA, F.P.; CALDAS, M.P. (Org.). Cultura organizacional e cultura brasileira. São Paulo: Atlas, 1997.

; ALCADIPANI, R. Jeitinho brasileiro, controle social e competição. Revista de Administração de Empresa - RAE, São Paulo, v. 39, n. 1, p. 6-12, jan./mar. 1999.

NARDUCCI, V.; VILLARDI, B.Q.; DUBEUX, V. Uma proposta de análise quantitativa da avaliação de desempenho por competências para minimizar as restrições culturais do Poder Judiciário ao modelo de administração pública gerencial: o caso de um Tribunal de Justiça. In: ENANPAD 2006, Salvador. Resumo dos trabalhos, p. 168. CD-ROM, APS - A 3082, Bahia.

PAULA, A.P. de. Por uma nova gestão pública. Rio Janeiro: FGV, 2005.

. Administração pública entre o gerencialismo e a gestão social. Revista de Administração de Empresas - RAE, São Paulo, v. 45, n. 1, p. 36-49, 2005 a.

PACHECO, Silvia Regina. Política de recursos humanos para a reforma gerencial: realizações do período 1995-2002. Revista do Serviço Público, ano 53, n. 4, p. 79106, out./dez. 2002.

RODRIGUES, S.B.; SÁ, R.C.R. de. A estrutura organizacional brasileira: aplicação do modelo de Aston e implicações metodológicas. Revista de Administração de Empresas - RAE, São Paulo, v. 24, n. 4, p. 158-174, out./dez. 1984.

SOUZA, E.P. de. Percepção de clima conforme escalão hierárquico. Revista de Administração de Empresas - RAE, São Paulo, v. 20, n. 4, p. 51-56, 1980.

. Clima e motivação numa empresa estatal. Revista de Administração de Em$\overline{\text { presas }}$ - RAE, São Paulo, v. 22, n. 1, p. 14-18, 1982.

STAKE, R. Case studies. In: DENZIN, N.; LINCOLN, Y. Handbook of qualitative research. United Kingdom: Sage Publications, 1994. 
TEIXEIRA, M.L.M.; ZACARELLI, L.M. A nova ambiência competitiva. In: HANASHIRO, D.M.M.; TEIXEIRA, M.L.M.; ZACARELLI, L.M. (Org.). Gestão do fator humano: uma visão baseada em stakeholders. São Paulo: Saraiva, 2007. p. 3-21.

VERGARA, S.C. Gestão de pessoas. São Paulo: Atlas, 1999.

VIEIRA, F.G. et al. Silêncio e omissão: aspectos da cultura brasileira nas organizações. RAE eletrônica, São Paulo, v. 1, n. 1, 11 p., jan./jun. 2002. 